\title{
The Irony of Irony: Irony Based on Truthfulness
}

\author{
Marta Dynel ${ }^{1}$
}

Received: 5 October 2016/Accepted: 27 December 2016/Published online: 11 January 2017

(C) The Author(s) 2017. This article is published with open access at Springerlink.com

\begin{abstract}
Drawing on a corpus of academic examples, this paper addresses the vexing notion of "verisimilar irony" from a philosophical-pragmatic perspective. This species of irony escapes a neo-Gricean definition of prototypical irony based on the assumption that the speaker utters what he/she believes to be false (cf. untruthfulness) in order to convey an implicit message which is to be gleaned on the basis of meaning opposition. Verisimilar irony, as defined here, relies on the speaker's expression of his/her evaluative belief at the level of Grice's what is said or implicated (if another figure is involved). A proposal is put forward that verisimilar irony does rest on untruthfulness, manifesting itself in as if implicature (untruthful implicature serving as an intermediate interpretative step) caused by flouting the Relation maxim. This as if implicature, in turn, necessitates meaning reversal so that the ultimate evaluative implicature can be inferred. In the course of the paper, the previous examples of verisimilar irony found in the scholarship (constituting the present corpus) are critically revisited to indicate that the spectrum of forms the focal type of irony can take is narrower than other authors have suggested. It is shown that some of the examples claimed to represent what is here called "verisimilar irony" either are not irony at all or represent other categories of the focal figure.
\end{abstract}

Keywords Verisimilar irony - Overt (explicit/implicit) untruthfulness - Evaluative implicature · What is said · First maxim of Quality · Maxim of Relation

Marta Dynel

marta.dynel@yahoo.com

$1 \quad$ University of Łódź, Łódź, Poland 


\section{Introduction}

The classical definition of the rhetorical figure of irony, which goes back to Quintilian (Bredin 1997), holds that irony is a figure of speech which conveys the opposite of what is expressed "literally", i.e. what the words uttered conventionally mean (see e.g. Sperber and Wilson 1981; Bredin 1997; Wilson and Sperber 1992; Colston and Gibbs 2007; Gibbs and Colston 2012). This view has come in for heavy criticism, but it has not ceased to be the departure point for contemporary researchers of irony. Grice's conceptualisation of irony, in turn, is taken to be the formalised version of the traditional approach.

According to Gricean thought, the use of the figure of irony generates implicature, ${ }^{1}$ i.e. implicated speaker meaning (speaker-intended meaning), that "is intimately connected with the expression of feeling, attitude, or evaluation" (Grice 1989b [1978]: 53-54). The thrust of Grice's (1989a [1975], b [1978]) few observations on irony is that this figure of speech carries a negatively (see Garmendia 2010, 2015) evaluative implicature of the target (most typically, a person, whether or not a listener to the utterance) with regard to a particular referent, i.e. an entity subject to evaluation (see Dynel 2013a, b, 2016a). Irony is presented as one of the figures of speech that give rise to particularised ${ }^{2}$ conversational implicatures under the header "Examples in which the first maxim of Quality is flouted" (Grice 1989a [1975]: 34). The first maxim of Quality, which reads "Do not say what you believe to be false" (Grice 1989a [1975]: 27), can be dubbed the maxim of truthfulness (cf. Wilson 1995; Wilson and Sperber 2000). Truthfulness and untruthfulness concern the speaker's beliefs, i.e. what the speaker believes to be true or false respectively, rather than objective truth and falsity (see Vincent Marrelli 2003, 2004; Dynel 2016c). Thus, since this maxim is flouted, i.e. overtly violated, ironic utterances may be seen as residing in overt untruthfulness. Also, irony originates in overtly pretending (Grice 1989b [1978]: 54) to communicate a meaning, or in making as if to say (Grice 1989a [1975]: 30, 31, 34, b [1978]: 40, 53), not in what is said. What is said is speaker meaning "closely related to the conventional meaning of the words (the sentence) he [the speaker] has uttered" (Grice 1989a [1975]: 25). No meaning arises as what is said in standard irony (which Grice must have addressed), though, for the speaker merely overtly pretends to be saying something only to communicate an implicature. Furthermore, in Grice's approach, the hearer supposes the speaker "to mean the negation of what he has made as if to say" (1989b [1978]: 53). Irony is seen as involving meaning negation/contradiction $^{3}$ (Grice 1989b [1978]), whereby one meaning is uttered, and

\footnotetext{
1 The term "implicature" is Grice's neologism for an act of implying (Grice 1989b [1975]: 24), which has grown to denote the meaning (conveyed by the speaker to be) inferred by the hearer.

${ }^{2}$ Having presented different floutings, including those inviting irony, Grice (1989a [1975]: 37) writes: "I have so far considered only cases of what I might call 'particularized conversational implicature' - that is to say, cases in which an implicature is carried by saying that $p$ on a particular occasion in virtue of special features of the context".

3 Other labels used synonymously in the literature on irony are: reversal, opposition, contradiction, and inversion.
} 
a different, typically antithetical (contradictory or opposite), meaning is intended (Grice 1989a [1975]).

However, some non-prototypical manifestations of irony divert from the Gricean conceptualisation in that they appear to rest on truthfulness, being based on expressed beliefs of which speakers are supportive, and thus, as Grice would put it, on what is said. In this vein, it is also sometimes observed that some irony disconfirms the assumption that irony is based on (overtly) pretended assertions (Recanati 2004; Soames 2008), insofar as it recruits sincere assertions ${ }^{4}$ (KumonNakamura et al. 1995; Colston 2000; Camp 2012; Stokke 2013). Secondly, as numerous authors have observed, Grice's definition, reminiscent of the traditional view as it is, fails to encompass irony which does not necessitate standard meaning negation, as epitomised by the type of irony discussed in this paper. Variously formulated, these claims reverberate across the literature, frequently as criticism of the Gricean account, pinpointing its inadequacy (e.g. Colston 2000; Attardo 2000; Utsumi 2000; Garmendia 2011).

At a glance, irony rooted in truthful statements, which communicate what the speaker believes to be true, here dubbed verisimilar irony (for a different, broader use of this label, see Partington 2006, 2007), does not appear to flout the first maxim of Quality or to necessitate meaning negation. It will be postulated here, however, that verisimilar irony does display Quality flouting, untruthfulness and meaning negation, albeit by making as if to implicate, i.e. at the level of as if implicature. The prime objective of this paper is to elucidate this non-prototypical type of irony on the strength of the existing literature, and to argue that it is amenable to neo-Gricean analysis. Nonetheless, Grice's view on irony must be considerably modified so that it can encompass verisimilar irony, an attempt at which will be made here. It should be stressed that the pragma-philosophical proposal put forward here is based on a rationalist (in a Cartesian sense) method of argumentation (as opposed to empirical methods reliant on cognitive experiments, for instance) and that it serves an explanatory function (see also Kapogianni 2011, 2016a, b), describing the focal type of irony in theoretical terms in order to offer a formal acid test for its presence. ${ }^{5}$ Such a formal test ${ }^{6}$ is in order, as evidenced by a corpus study of the alleged examples of verisimilar irony culled from the existing scholarship. On close inspection, most of these instances do not evince the central characteristics of verisimilar irony.

This article is structured as follows. "Corpus Data in the Research on Irony" gives a critical overview of data selection strategies in (corpus) studies of irony, laying the foundations for the present paper. "Approaching Verisimilar Irony" depicts the vexing category of irony in the focus of attention, taking as its departure

\footnotetext{
4 Grice's what is said is not synonymous with asserting, i.e. an act of presenting a statement one utters as true. What is said is germane to any utterance form as long as the Cooperative Principle and maxims are observed. Also, Grice (1989b [1978]: 51) seems to differentiate between "saying" and "asserting" when he talks about a speaker who aims to "assert (or otherwise say)" (see Dynel 2017b).

5 No attempt is made to account for speakers' or hearers' actual cognitive processes underlying the production and reception of irony, which is the goal of cognitive studies.

6 This test does not include the prosody of irony, which is only one of the cues for its presence, but not a necessary condition for its presence.
} 
point one proverbial example that reverberates across the literature. This instance is scrutinised against the backdrop of previous discussions and is shown not to operate on literal expression, contrary to the well-entrenched view, but on a subordinate figure of speech. As a result, two subtypes of verisimilar irony are distinguished, depending on whether they capitalise on (truthful) what is said, or on making as if to say and truthful implicature. "Previous Grice-Inspired Accounts of Verisimilar Irony" gives a critical overview of the existing neo-Gricean approaches to verisimilar irony, pointing to their shortcomings, and indicating that yet another neo-Gricean account is in order, which is duly provided in "A Neo-Gricean Approach to Verisimilar Irony". In "Examples of Verisimilar Irony in the Literature", a few examples of verisimilar irony are examined in the light of the interpretative model proposed here, and a few formal characteristics of this irony are briefly depicted. Since verisimilar irony turns out to be a narrow-scope phenomenon which manifests itself in a limited number of forms, attention is paid also to a selection of problematic examples viewed by other authors as representing what is here dubbed verisimilar irony. It is shown that these are not cases of verisimilar irony and, frequently, no irony at all. Thereby, any potential criticism that the interpretative model offered here does not encompass such instances is diffused. The article closes with a number of general remarks in "Conclusions" section.

\section{Corpus Data in the Research on Irony}

In his 2007 book, Partington opens the discussion of irony by bemoaning the fact that the extant scholarship employs limited data: "Artificial examples and isolated individual instances are recycled from paper to paper, whilst the experimental work tends to expose subjects to rather simple invented examples and situations" (Partington 2007: 198). Indeed, even to date, most of the theoretically-oriented linguistic literature, in tandem with experimental research, devoted to irony has been based on isolated examples, invented or anecdotal, which are further taken for granted and circulated in the scholarship. Nonetheless, recent years have seen a steady flow of corpora-based research on irony, which can be divided into several strands depending on the authors' data collection methods (see also Burgers et al. 2011).

Some studies (e.g. Barbe 1993, 1995; ${ }^{7}$ Claridge 2001; Lucariello 1994; Partington 2007; Shelley 2001; Taylor 2015; Dynel 2017c) capitalise on the occurrence of the labels "irony" and its derivatives in datasets. Most recently, some corpora have focussed on hashtag as a marker of irony in datasets based on technologically-mediated communication (Reyes et al. 2012, 2013). The "\#irony" or "\#sarcasm" label signals that a language user perceives his/her utterance as

\footnotetext{
7 Barbe (1993, 1995) coins the term explicit irony with reference to language users' verbal reflections on situations that they perceive as ironic and comment on by dint of explicit irony markers. These involve the use of the word "irony" or its derivatives. Consequently, she dubs the respective rhetorical figure "implicit irony". This terminology is problematic. Implicitness inheres in the figure of irony, and thus in ironic utterances. It is then a terminological and theoretical mistake to term "irony" utterances carrying people's recognition of situational irony.
} 
ironic at the time of production and indicates this for the sake of the receivers' understanding. Overall, the studies done on the basis of American and British English, however, adduce evidence that the lemma "irony" usually (but not always) signals language users' recognition of situational irony and bears little relevance to the research on the rhetorical figure. Thus, this method misses many, if not most, instances of the rhetorical figure, which inherently involves implicitness and, typically, is not indicated via metalanguage. Such an approach is then useful only if the focus is on situational irony or lay understandings. Generally, even if the label "irony" in popular parlance should sometimes concern something else than situational irony, language users' understandings may depart from academics' understandings (cf. Gibbs and Colston 2007; see Dynel 2017c) and need not involve the trope, which is what scholars typically wish to investigate. Additionally, using a single lemma as the search word cannot possibly yield all instances of irony in a chosen discourse database, leaving all un-labelled instances unaccounted for.

The second major methodological strategy consists in tracing the occurrence of cues for, or concomitants of, irony in chosen datasets (for a good overview of such cues, see Burgers et al. 2012). One of such cues is laughter signalling the production and/or reception of irony in spoken discourse (Partington 2007; Pelsmaekers and Van Besien 2002). The main shortcoming of this search method is that it does not allow for the differentiation between humorous irony and other humorous stimuli which evoke laughter, and thus it depends on the author's ultimate decision on whether or not a given instance can be classified as irony. On the other hand, nonhumorous irony (which objectively carries no potential for humour and is not cued as such) or irony which does have humorous potential but is not recognised as being humorous by the hearers, and/or indicated as such by the speakers, is overlooked (on (non)humorous irony, see Dynel 2013b, 2014).

By the same token, verbal cues for irony will not be fully reliable, either, necessitating the author's decision-making, and again narrowing down the scope of the phenomenon to those instances which involve given search words. The rhetorical concomitants of irony, such as hyperbole or meiosis, are independent phenomena and cannot be taken as unequivocal cues for its presence, not to mention the fact that they cannot be automatically extracted per se. The same holds for conventional irony, which relies on specific lexemes, such as "nice" or "fine" (see Giora 2003; Alba-Juez $1998^{\circ}$ ). These lexemes can also be seen as verbal cues for irony. Nonetheless, such words constitute only a small proportion of the manifestations of irony, and they need not always involve the figure, being used in literal senses. On the whole, automatic searches based on verbal cues would yield inadequate results: too narrow (insofar as they limit the findings to chosen search words and miss the instances of irony in which such cues are absent) and, at the same time, too broad (inasmuch as the cues are not exclusive to irony).

What poses the greatest problem for irony researchers is that the focal figure always involves implicating, and the implicatures arising from irony seem to escape any known search engines. This explains why in most of the (still

\footnotetext{
$\overline{8}$ She claims that such irony does not depend on implicature, though.
} 
relatively few) corpus studies of irony, the authors compile their corpora manually on the basis of their intuitions (e.g. Gibbs 2000; Alba-Juez 1998; Weizman 2001), sometimes supported by non-academic raters' decisions reflecting folk understandings (e.g. Eisterhold et al. 2006). In research involving very large datasets, even if some filters and search engines are used to harvest preliminary data, the examples of irony are ultimately hand annotated, also based on the authors' judgements. This typically leads to dissecting chosen classes of irony, such as ironic similes (Veale and Hao 2009; Veale 2013) or negative constructions (Giora et al. 2014). The judgements of such specific species of irony, admittedly, stand less chance of being impaired by personal intuitions of what irony involves.

Likely, in order to avoid this personal bias, Burgers et al. (2011, 2012, 2013) propose a discourse selection procedure, based on several interpretative steps: dividing discourse into units of analysis, determining that a unit is evaluative, constructing a scale of evaluation about the referent and placing on it the intended and literal evaluation, and deciding if the intended evaluation is relevant to the context and co-text (if it is, the clause is ironic). However, the model is premised on an assumption that ironic utterances are inherently evaluative (see also Partington 2006, 2007). Even though the authors do acknowledge the fact that evaluation is not always present in the literal form of expression, and introduce the notion of evaluative connotation, as well as implicit evaluation, they provide little explanation of how this implicitness/connotation is to be sought. Nor do they account for the fact that some ironic utterances are not couched in any, explicitly or implicitly, evaluative expressions (Dynel 2013a). Such may be easily overlooked.

The most reliable method of compiling ironic data to date appears to be manual selection of examples premised on proposed definitional components of irony (Kapogianni 2011, 2013, 2014, 2016a, b). This method also has obvious limitations, though. It carries the danger of circularity and may yield skewed results if the criteria proposed on the basis of previous literature and the authors' elaborations are inadequate, but it seems to be the only way comprehensive lists of novel examples can be compiled.

This paper, nevertheless, rests on yet another approach in order to define the nonprototypical and, admittedly, empirically rare type of irony. The language data to be analysed are drawn from the existing scholarship. The focus is thus on the precious few examples that other researchers have recognised as instances of what is here called "verisimilar irony". Whether constructed or overheard by the researchers, these instances are presented in the literature as the prototypical cases of the nonprototypical type of irony. As will be shown here, they do not always meet the conditions for (verisimilar) irony.

\section{Approaching Verisimilar Irony}

What is here referred to as "verisimilar" irony has been recognised and discussed with the use of diversified terminologies and different scholarly approaches (e.g. Haverkate 1990; Gibbs and O'Brien 1991; Hamamoto 1998; Sperber and Wilson 1998; Colston 2000; Attardo 2000; Utsumi 2000; Partington 2006, 2007; Garmendia 
2011; Camp 2012). Very frequently, when this problematic type of irony is addressed, one proverbial example (rarely discussed in detail) is given along the following lines:

(1) A mother enters her son's messy room and says, "I like/love children who keep their rooms clean" (Gibbs and O'Brien 1991: 525-526; Barbe 1995: 27; Hamamoto 1998: 261, 267; Sperber and Wilson 1998: 289; Utsumi 2000: 1780; Partington 2006: 187, 2007: 1549; Kapogianni 2011: 54)

A statement can be ventured that some opposition in lexical senses, such as "love" versus "hate" or "clean" versus "untidy", may be involved in inferring speaker meaning, which amounts to criticising the child's messy room. However, the intended meaning is not a matter of standard meaning reversal whereby the implicated meaning is a negation of the untruthful literal expression.

On an alternative account, nonetheless, it could be claimed that this example does necessitate meaning negation, where the main verb and the adjective in the relative clause are replaced by their corresponding opposites: "I hate children who keep their rooms untidy". 9 This is essentially what Yamanashi (1998: 273) suggests in reference to a different but structurally similar case: "We admire those who are honest". Even though Yamanashi (1998) does not explicate this instance, it seems to involve a truthful statement uttered in the context of the hearer's dishonest behaviour, which is to be understood as "We despise those who are dishonest" (Yamanashi 1998: 273). This simplified interpretation fails to bring out the distinctive feature of the type of irony in question, that is the speaker's literal truthfulness (a truthful meaning coinciding with what is said) and the reason for performing the negation of the two evaluative lexemes. Moreover, even though the negation-based interpretations may indeed carry truthful meanings, they do not appear to be the focal critical messages that the speakers wish to communicate in the contexts at hand, such as: "I disapprove of your untidy room" and "I despise your dishonesty". Without these implicatures carrying criticism of the hearers, the negation-based paraphrases purport to be contextually irrelevant. Even if the implicatures with adequate referents were added to rectify this irrelevance, a query would persist concerning the reason for performing the twofold negation. This pattern of interpretation is then untenable.

Partington (2007) seems to follow a train of thought similar to Yamanashi's (1998). In his evaluation reversal approach to irony, Partington (2007) propounds an interpretative model which holds that the evaluation communicated by any ironic utterance needs to be reversed in order to be relevant to a given context. In reference to the canonical example, which he views as a case of verisimilar irony, Partington (2007: 1564) suggests that the mother is implying a reversed evaluation, i.e. "hatred" rather than "love": "I don't like children (that is, you) who have untidy rooms" (cf. Yamanashi's 1998 similar elaboration, yet devoid of the specified referent of evaluation). A question arises as to what (in theoretical terms) triggers

\footnotetext{
9 All the attempts at reconstructed implicatures made in the course of this paper are just tentative suggestions, based on the simplest possible operations, style and functional language use notwithstanding. The exact wording might then be changed for the sake of more natural language use.
} 
the meaning reversal process and promotes this implicature. Additionally, what Partington does not spell out is that the reversal of the evaluative verb and adjective involves also a change of the referent of the focal evaluation (cf. "children's rooms" vs. "your room"). This seems to be based on a logical syllogism: "I don't like children who have untidy rooms" and "You are a child and your room is untidy", and hence "I don't like you for having an untidy room." 10

Essentially, in verisimilar irony, the literal expression is not contradictory to the intended meaning. On the contrary, it may be regarded as part of speaker meaning, technically, what is said, which serves as the springboard for the pivotal evaluative implicature. Thus, the intended meaning is not a matter of standard (propositional or otherwise) meaning reversal, whereby the intended meaning is an inversion of the one expressed but not meant. Such irony is based on literally expressed genuine beliefs, and thus what is said, as in the following example:

(2) "I really appreciate cautious drivers," said to a neurotically cautious driver by his companion (Wilson 2006: 1726)

This utterance carries what is said: "I really appreciate cautious drivers" and invites an implicature along the lines of: "You're so cautious a driver that you are annoying.".

What is here dubbed verisimilar irony is typically claimed to reside in truthful literal meanings, here conceptualised as what is said. Alternatively, however, when another Quality maxim flouting is involved, a truthful implicature (but no what is said) is engendered as an intermediate level of meaning. This happens when a verisimilar ironic utterance is couched in a hyperbole, meiosis or metaphor, ${ }^{12}$ which involve independent floutings of the first maxim of Quality (cf. Grice 1989a [1975]: 33-34). When prototypical irony (based on making as if to say and meaning reversal) co-exists with any of the other Quality-based figures of speech, the latter are comprehended logically prior to the ironic meaning (on metaphor, see e.g. Yamanashi 1998; Stern 2000; Camp 2006, 2012; Popa 2009; Dynel 2016d) and this obtains also for verisimilar irony. Therefore, in verisimilar irony that deploys a subordinate Quality-based figure, making as if to say is always present but is independent from the irony per se, which essentially stems from a truthful meaning, i.e. a truthful ironic implicature promoted by the hyperbole, meiosis or metaphor, which is subject to further interpretation.

Interestingly, this appertains to the canonical mother example. Contrary to popular opinion, the mother's utterance does not constitute a truthful assertion, and thus what is said. What does not appear to have been recognised in the previous

\footnotetext{
${ }^{10}$ I would like to thank an anonymous referee for bringing this to my attention.

11 Wilson (2006) states that this instance does not centre on what is "blatantly false" and that no corresponding implicature is involved. However, if this utterance is to represent irony, an implicature must arise.

12 These are markedly distinct phenomena, which should be analysed in different ways (see e.g. Gibbs and Colston 2012). Nonetheless, from a Gricean perspective, they share one crucial feature, namely they originate in the flouting of the first maxim of Quality.
} 
discussions of this example is that the mother's utterance rests on a hyperbole, ${ }^{13}$ insofar as love and hatred of children, let alone all children, can hardly be developed merely on the grounds of whether or not they keep their rooms clean. The example can be dissected as follows:

(2a) Hyperbolic/overtly untruthful utterance; making as if to say: "I love children who keep their rooms clean"

(2b) Truthful ironic implicature: "I like it a lot when children keep their rooms clean"

(2c) Ultimate evaluative implicature: "I do not approve of your untidy room"

A truthful ironic implicature comes into being once the hyperbole is embraced in the first stage of interpretation. No what is said is present, due to the presence of hyperbole ("love"), a layer of meaning distinct from the ironic implicature. Consequently, this example should be viewed as being based on hyperbole-based making as if to say, and hence overt untruthfulness inviting an intermediate truthful ironic implicature (e.g. "I like it a lot when children keep their rooms clean"), which acts as a departure point for the focal evaluative implicature, which consists in criticising the specific child (e.g. "I do not approve of your untidy room"). In addition, it can be argued that this instance of verisimilar irony as such will work similarly when no hyperbole is involved and the evaluative implicature arises directly from what is said (e.g. "It makes me happy to see children who keep their rooms clean" or "I like to see a child's room that is clean").

It must be underscored that some attention has been paid in the literature to verisimilar irony which pivots on what is said, frequently referred to as "true" or "sincere" "assertions" (Kumon-Nakamura et al. 1995; Colston 2000; Camp 2012; Stokke 2013), whereas the alternative subtype (where no assertion or any other form of what is said is present) does not appear to have been recognised so far.

\section{Previous Grice-Inspired Accounts of Verisimilar Irony}

A number of attempts have already been made to account for what is here called verisimilar irony with reference to Grice's notions. Some of them will be succinctly reviewed now and their shortcomings will be indicated (whilst a few other claims will be addressed in "A Neo-Gricean Approach to Verisimilar Irony", where other authors' examples are discussed). Only a few of the tenets proposed previously are endorsed here.

Attardo's (2000) complex proposal of relevant inappropriateness germane to all irony appears to have arisen from his criticism of the Gricean account on the grounds that it does not capture irony which fails "to violate a maxim" (2000:

\footnotetext{
13 Barbe (1995) does mention that this example is contingent on a hyperbole, but her view on its workings is questionable. Barbe states that the speaker loves not all children but just her children, especially when their rooms are clean. However, this is precisely what the speaker does not wish to communicate in this context. The mother's aim is to criticise her child for the messy room.
} 
$817),{ }^{14}$ by which he seems to mean an ironic utterance's failure to flout the first maxim of Quality. Attardo (2000) proposes that such an ironic utterance entails inappropriateness in a given context, albeit being relevant. Appropriateness applies if all presuppositions of an utterance are identical to, or compatible with, those of the context, which does not hold for irony. In Attardo's (2000) view, appropriateness is truth-sensitive.

A query may be raised as to why Attardo's (2000) postulate, which he propounds as an extension of the Gricean approach, should resort to the markedly different, competing research tradition, viz. Relevance Theory, endorsing a revised version of the notion of (contextual) relevance. Attardo's (2000) model, therefore, collates disparate, irreconcilable tenets on relation/relevance. The relevance-theoretic approach is premised on the assumption of relevance (importance) of a (verbal) stimulus, which must always be sought, predicated on the effects/costs ratio. By contrast, in the light of the Gricean account, the Relation (not "relevance", as Attardo calls it) maxim may be flouted so that implicatures should arise. Although the rationale underlying "relevant inappropriateness" is intuitively appealing: an ironic utterance is invariably contextually inappropriate, but it is at the same time relevant/sensible, Attardo's (2000) proposal is overburdened with terminological and methodological problems consequent upon his (disputable) interpretation of Grice's postulates. In actual fact, Attardo's (2000) "relevant inappropriateness" appears to correspond to the simple case of flouting the Relation maxim. Put in Gricean terms, the speaker's utterance is inappropriate in the context at hand, an explanation for which must be sought on the grounds of the underpinning Cooperative Principle, whereby a relevant (in Grice's sense) intended meaning in the form of an implicature is fostered. Irrespective of its bedrock premises, another shortcoming of Attardo's (2000) postulate is that it does not account for how exactly the ironic interpretation is to be sought. Yet another query is that the notion of relevant inappropriateness could pertain to non-ironic utterances, as long as contextually inappropriate but relevant or simply contingent on the Relation maxim floutings. Therefore, Attardo's (2000) proposal fails to tease out the differentiating features of (verisimilar) irony, apart from being convoluted due to the "theoretical mergers" he proposes.

On the other hand, Colston (2000) supports the Gricean conceptualisation of irony, albeit extending the list of maxims that can be flouted to generate irony (see "Examples of Verisimilar Irony in the Literature" for criticism). He also brings to focus the notion of contrast of expectations, desires, preferences, or social norms against the actual events, which should, as is argued here, be formally depicted as what the speaker believes to be true events. In Colston's (2000) view, therefore, irony comprehension (and, it could be added, production) necessitates the flouting

\footnotetext{
14 In Attardo's (2000) view, based on what seems to be an ill-advised interpretation of the Gricean account of the Cooperative Principle (see Dynel 2009), irony is non-cooperative. In reality, irony is cooperative, in the Gricean sense, as long as the speaker produces it rationally and means to be understood, thereby observing the Cooperative Principle, while flouting the first maxim of Quality. Attardo (2000), however, avers that irony violates the Cooperative Principle (which, as the principle of rationality, can hardly be violated), as well as "the maxim of Quality" (sic), whilst it is only the first maxim of Quality that is legitimately flouted.
} 
of any of the Gricean maxims and what they portray, namely the contrast which can be achieved by overtly pretending (see Dynel 2017a) to assert the expected events or by invoking them while speaking earnestly, and thereby being truthful or pragmatically sincere. The latter stipulation concerns verisimilar irony, which resides in truthful utterances evoking expectations which appear to have been defeated or norms which have been violated.

According to Colston (2000), irony which does not involve pretending "to advocate or assert expected events in contrast with reality" achieves this contrast by "invoking those alternative events in the mind of the speaker while speaking earnestly" (2000: 316). This may be right, but it does not seem to delineate the scope of irony based on truthfulness, insofar as utterances which do meet this definition need not be invariably considered ironic (which may not be a problem for Colston's analysis as such). For instance, eating too spicy a steak prepared by his wife, who has made palatable steaks for many years, a man says: "Something must have happened to your taste buds". This utterance is not ironic, even though it flouts several maxims, in accordance with Colston's (2000) proposal, yet not the first maxim of Quality, and alludes to the interlocutors' common ground and the man's expectations, conveying an implicit, evaluative message: "You probably cannot feel the taste of this steak, and it is not nice". Colston's (2000) definition is then too broad, unless another stipulation is added to it, namely the flouting of the Relation maxim, ${ }^{15}$ which he does address in his paper, but not as the sine qua non for pragmatically sincere irony. Colston (2000) only mentions that irony may sometimes rely on a pragmatically sincere utterance which flouts the maxim of Relation, insofar as it refers to a situation different from the one that has occurred. Generally, although it does contain a number of apt observations, Colston's (2000) discussion fails to extract the essence of verisimilar irony or distinguish it from other implicit phenomena.

Thirdly, Camp (2012: 607) observes that some irony (which she dubs "sarcasm") can "target implicatures that would be generated by a fully sincere utterance of a sentence which is itself genuinely asserted." It can be extrapolated from her analyses that the ironic/untruthful meaning subject to reversal can arise as implicature which, in turn, originates in a truthful assertion. This proposal's basic drawback is that it is very general and can only be better understood based on examples. Otherwise, it is difficult to grasp the ways in which the ironic implicatures come into being. Regrettably, the examples that Camp (2012) provides seem to offer little help, being disputable (see "Examples of Verisimilar Irony in the Literature"). Moreover, it is difficult to tell whether Camp's (2012) general conceptualisation would capture the canonical mother example, and if so, how exactly it should be interpreted. Generally, Camp (2012) gives no unequivocal formula for how the implicature that irony "targets" is reached, whilst it seems that the range of implicatures stemming from what is said $^{16}$ and inviting ironic

\footnotetext{
15 Colston (2000), however, calls it the "Relevance" maxim, and uses the labels "violation" and "flouting" interchangeably, which does not adequately represent Grice's parlance and proposals.

16 Alternatively, verisimilar irony may operate on making as if to say, thanks to another figure residing in flouting the first maxim of Quality (cf. "Approaching Verisimilar Irony”).
} 
interpretations is very narrow, much narrower than Camp (2012) proposes, based on a few (dubious) examples. Finally, Camp (2012) claims that this assertion-based irony should be classified as the "propositional" type, together with standard meaning-negation irony. By contrast, it is here postulated that this is more a matter of a distinct category of irony, insofar as the implicated meaning's derivation is different from standard propositional negation irony (cf. Dynel 2013a).

Last but not least, Kapogianni (2011: 54) observes that ironic utterances manifest intrinsic "counterfactuality", either in the form of a direct contrast with reality (which is here reconceptualised as what the speaker believes to be true, rather than objective truth), or in the inferences an utterance promotes, which bears relevance to verisimilar irony. Kapogianni (2011: 54) thus suggests that the counterfactual (here, untruthful) meaning that needs to be negated can be the one "inferred" by the hearer, not the one "explicitly expressed" by the speaker. ${ }^{17}$ Also, the natural inference that "I like $x$ " in a context means that " $x$ is true in that context" is subject to negation (Kapogianni 2011: 54). The pending question is why and how this should happen. Regrettably, Kapogianni (2011) provides no unequivocal explanation of the meaning derivation process. However, she rightly notes that it is the inferred meaning, here conceptualised as implicature, that is counterfactual (here, untruthful) and she underscores the significance of context, a train of thought that will be followed here (see "A Neo-Gricean Approach to Verisimilar Irony").

An attempt will now be made to elucidate the mechanics of verisimilar irony. Similar to Kapogianni (2011) and Camp (2012), the present work takes as its departure point a Gricean rational reconstruction theory of how meaning is inferred in the case of ironic utterances, with a distinction being drawn between verisimilar irony and standard irony which rests on overt untruthfulness (cf. Dynel 2013a, 2016c).

\section{A Neo-Gricean Approach to Verisimilar Irony}

Verisimilar irony seems to escape explanation in the light of Grice's original account of irony, which does not mean that the latter cannot be modified so that it should capture irony based on truthful meanings, whether what is said $^{18}$ or implicature. The latter, as argued in "Approaching Verisimilar Irony", comes into play when a non-ironic flouting of the first Quality maxim is observed and rectified at the first stage of interpretation, before the ironic meaning is dissected. If an utterance is couched in a Quality-based figure of speech other than irony, it cannot be considered in the context of what is said but it does foster a truthful implicature, an intermediate level of meaning (cf. the mother example). Thus, contrary to

\footnotetext{
17 It should be stressed also that the hearer's and speaker's perspectives are (ideally) in tune: what the hearer infers is actually what the speaker implies, at least according to the explanatory theoretical models of irony.

18 A query may arise as to whether what is said can ever be untruthful. Whilst Grice (1989a [1975]) priorities the first maxim of Quality, whereby flouting the maxim leads to making as if to say and its covert violation is excluded from the model, neo-Gricean analyses may indeed encompass lying, which is tantamount to covertly untruthful what is said (Dynel 2011, 2016b).
} 
popular opinion, the generalisation that verisimilar irony originates from assertions, truthful statements, or truthful literal meanings should best be avoided. In essence, verisimilar irony can be deemed to reside in truthful meanings, which may arise at the level of what is said or at the level of implicature. However, even if the speaker may be expressing his/her belief, this is not what he/she means to communicate primarily in the context at hand (cf. Sperber and Wilson 1998), at least not as the central message. The speaker uses the expression of his/her true belief as a springboard for the focal evaluative implicature. It is this implicature that is the primary meaning (see Jaszczolt 2009) that the speaker intends to get across.

In either form, based on truthful what is said or implicature, verisimilar irony may be seen as invalidating the claim that overt untruthfulness and meaning reversal are the central characteristics of all irony. Indeed, as originally conceived by Grice, untruthfulness anchored in flouting the first maxim of Quality can hardly encompass verisimilar irony, which is sometimes regarded as corresponding to "factual reality" (Myers Roy 1978: 172). This notion should be substituted for "truthfulness", for verisimilar irony operates on the genuine expression of evaluation, or subjective statement of facts. Also, irony does not always refer to verifiable facts per se, and reality depends on individual perception and belief about what the truth is. This also tallies with Grice's formulation of the first maxim of Quality, which concerns the speaker's beliefs. One might then conclude that verisimilar irony does not capitalise on untruthfulness, for a verisimilar ironic utterance does not rely on flouting the first maxim of Quality (optional subordinate figures of speech aside).

However, untruthfulness is not a homogeneous notion. Firstly, it can be divided into overt and covert untruthfulness (Vincent Marrelli 2003, 2004), the former being central to figures of speech, notably irony (as well as metaphor, metonymy, meiosis and hyperbole), and the latter underlying deception (see Dynel 2016c). Overt untruthfulness is meant to be recognised by the hearer. Secondly, overt (and covert) untruthfulness bifurcates into explicit untruthfulness and implicit untruthfulness. The overt explicit type, which lies at the heart of prototypical irony, shows on the utterance level and involves making as if to say. On the other hand, overt implicit untruthfulness pertains to the level of implicature generated on the basis of the subordinate truthful meaning, whether what is said or implicature. Consequently, a proposal is here formulated that verisimilar irony deploys overtly untruthful as if implicature arising from the truthful what is said or implicature, and that this as if implicature necessitates meaning reversal conducive to the central evaluative implicature. As if implicature is overtly untruthful meaning that does not constitute speaker meaning, and which only serves as a potential inferential step leading to the focal evaluative implicature in verisimilar irony. ${ }^{19}$ The process of this implicature's emergence will be depicted in the course of this section.

\footnotetext{
19 Another manifestation of an untruthful as if implicature concerns cases of irony combined with two other Quality-based figures of speech (viz. metaphor and metonymy), where no what is said is present (see Dynel 2016d).
} 
It is argued here that a hallmark of verisimilar irony is contrast between a truthful meaning and the context in which it is communicated (cf. Gibbs and Colston 2012). Essentially, in verisimilar irony, what is said or what is implicated (in the case of non-ironic floutings of the first maxim of Quality) is truthful and reflects the speaker's genuine belief, but it is inappropriate/inapplicable/irrelevant (in Grice's sense) in a given context (cf. Sperber and Wilson 1998; Gibbs and Colston 2012) and towards the referent appertaining to the target of irony. Specifically, as evidenced by the mother example, the speaker's truthful evaluation is inapplicable in the context with regard to the referent (the state of the child's room), and more generally the target of evaluation (the child). On a deeper level, verisimilar irony manifests a contrast between the evaluative belief the speaker expresses and the belief he/she holds about the referent of irony manifest in the context, as perceived by the speaker and, typically, the hearer. Usually, but not always, this context coincides with objectively verifiable facts. Also, this context may be non-verbal (e.g. an untidy room which interlocutors can see, or neurotically careful driving) or may be verbal, determined by the import of the preceding utterances, which can be thought of as co-text, as construed by the speaker and, ideally (for irony is to succeed communicatively), by the hearer as well. Additionally, this context is at odds with his/her expectations or beliefs, whether or not conscious, as represented by the expressed belief, and thus it deserves to be commented on ironically and evaluated negatively. Finally, it must be underscored that the contrast between the truthful meaning and the context should not be mistaken for the one concerning the overtly untruthful making as if to say and the contextual factors to which it refers (cf. Kapogianni 2013, 2016a), which is typical of standard meaning reversal irony based on explicit untruthfulness.

The interpretative model proposed here is premised on an assumption that the contrast between a truthful meaning and the context can be conceptualised as the flouting of the Relation maxim. In other words, because they are transparently at odds with the context, truthful, verisimilar ironic meanings are inherently based on flouting the Relation maxim, i.e. "Be relevant" (Grice 1989a [1975]: 27). It must be underscored that the Relation maxim is not dependent merely on discoursal relevance, which Attardo's (2000) idea of relevant inappropriateness tacitly and unwittingly reflects. It is Grice himself (1989a [1975]) who appears to have indicated the vexing status of the "Be relevant" maxim, noting that its "formulation conceals a number of problems that exercise me a good deal: questions about what different kinds and focuses of relevance there may be, how these shift in the course of a talk exchange, how to allow for the fact that subjects of conversation are legitimately changed, and so on" (Grice 1989a [1975]: 27). Interestingly, Grice addresses this maxim and its non-fulfilment in two distinct ways.

Discussing the origin of conversational implicatures, Grice (1989a [1975]: 32) introduces a group of "examples in which no maxim is violated, or at least in which it is not clear that any maxim is violated", which he exemplifies by two short exchanges: "A: I am out of petrol. B: There is a garage round the corner." and "A: Smith doesn't seem to have a girlfriend these days. B: He has been paying a lot of visits to New York lately." Whilst in contemporary neo-Gricean studies, these two examples will be regarded as flouting the Relation maxim, Grice avers that in each 
of the examples, "the speaker implicates that which he must be assumed to believe in order to preserve the assumption that he is observing the maxim of Relation" (1989a [1975]: 32). At a glance, the replies provided by the two B's do not look as if they are immediately related to the preceding turns, given their semantic contents. This is why they depend on maxim floutings. The speakers produce overtly irrelevant replies, and it is the recognition of this fact that guides the hearers towards seeking the focal implicatures, where the Relation maxim is observed. The rational speakers must wish the hearers to observe a tacit connection between the two parts in the adjacency pairs, together with the importance/relevance of the replies, and glean the implicatures (i.e. "You can get some petrol in a garage round the corner" and "Smith may have had a girlfriend in New York.").

Another pertinent Relation-based instance (in Grice's (1989a [1975]: 32) view different, though) is as follows: "Suppose that A and B are talking about a mutual friend, $\mathrm{C}$, who is now working in a bank. A asks $\mathrm{B}$ how $\mathrm{C}$ is getting on in his job, and B replies, Oh quite well, I think; he likes his colleagues, and he hasn't been to prison yet." (Grice 1989a [1975]: 24) in order to implicate that C is "potentially dishonest" (Grice 1989a [1975]: 31). With regard to this example, Grice uses the ambivalent term "apparent violation" of the "Be relevant" maxim (Grice 1989a [1975]: 31, 35). This apparent violation stands vis-à-vis the "real violation", which appears to mean "flouting". ${ }^{20}$ Specifically, addressing the issue of an implicature "achieved by real, as distinct from apparent, violation of the maxim of Relation", Grice (1989a [1975]: 35) provides an example of discoursal exploitation of the Relation maxim, whereby the topic of the exchange is drastically changed to imply that the preceding turn was a social faux pas. This is a matter of starting a new topical strand in reply to the preceding turn, as evidenced by the following example:

At a genteel tea party, A says Mrs. $X$ is an old bag. There is a moment of appalled silence, and then B says The weather has been quite delightful this summer, hasn't it? B has blatantly refused to make what he says relevant to A's preceding remark. He thereby implicates that A's remark should not be discussed and, perhaps more specifically, that A has committed a social gaffe.

(Grice 1989a [1975]: 35)

It may seem, therefore, that any "real violation" of the Relation maxim must involve the speaker's implicature that he/she is unwilling to refer to the previous utterance. "Real violation" will display very narrow applicability, i.e. for topic shifts, whilst the "apparent violation" will coincide with the contemporary understanding of the Relation maxim floutings.

Regardless of the clarity of the Gricean account of the two types of nonfulfilment of the Relation maxim and Relation-driven implicatures, it appears that the Relation maxim manifests itself in two forms: at the level of discoursal coherence and at a deeper level of the communicated meaning's significance in a given context, whether verbal or non-verbal. In verisimilar irony, the speaker flouts

\footnotetext{
${ }^{20}$ The notion "real violation" is presented under the heading of maxim flouting/exploitation (Grice 1989a [1975]: 33) and it should not be mistaken for "violation" understood as covert non-fulfilment of a maxim.
} 
the Relation maxim understood primarily in the latter sense, even though discoursal incoherence may also come into play.

In view of the above, an interpretative/explanatory formula can now be postulated for verisimilar irony. Albeit truthful, what is said or implicature carried by a verisimilar ironic utterance centres on flouting the Relation maxim, inasmuch as this truthful meaning does not tally with the context (and the speaker's belief about it), of which the hearer needs to be aware on the strength of the context available to him/her, which determines the nature of the evaluated referent. For instance, in the proverbial mother example, the speaker is truly appreciative of the subject of non-ironic evaluation, namely children who keep their rooms clean, whilst the ironic referent, the room at which the woman is looking, is untidy (cf. the truth), and she must consider it such (cf. truthfulness). Also, given its contextual irrelevance (in Grice's sense), the truthful evaluative meaning cannot exhaust speaker meaning, which the hearer is meant to recognise in order to arrive at the focal implicature. Being at odds with the non-verbal context, the truthful evaluative meaning may be seen as flouting the Relation maxim. To render the truthful meaning and the context compatible, or to rectify the Relation maxim's flouting, the hearer may be seen as inferring an as if implicature (in the mother example: "I like your keeping your room clean now"). Even though this may be a good candidate for the meaning motivating the speaker's utterance in the context, it can be only an as if implicature. This is because it is overtly untruthful and it cannot constitute speaker meaning. The as if implicature serves as the inferential basis for the central evaluative implicature, because it shows the flouting of the first Quality maxim, which necessitates meaning reversal of two kinds, ${ }^{21}$ concerning the real context in the focus of attention ("Your room is not clean") and the nature of the evaluation pertinent to this real context, which must be made opposite to the evaluation pertinent to the context opposite to the actual one ("I don't like it"). This twofold meaning reversal is ultimately conducive to the implicature which evaluates negatively the target of irony (the child) in regard to the focal referent (the state of the room) (e.g. "I don't like your room being messy"). A statement may be ventured that verisimilar irony presents the same features as prototypical irony, but on the level of as if implicature, not making as if to say. Whilst communicating a truthful meaning which flouts the Relation maxim, the speaker makes as if to implicate another piggybacked meaning which is subject to meaning negation and promotes the focal evaluative implicature. The following interpretative/analytic steps can be reconstructed:

1. Recognition of truthful speaker meaning: what is said or implicature

2. Recognition of flouting the Relation maxim in the context at hand

3. Rectifying the Relation maxim flouting by finding an as if implicature, which is compatible with the context but is overtly untruthful

4. Reversing the meaning of the as if implicature so that it is truthful, compatible with the context and representative of the speaker's genuine evaluation, which leads to the focal evaluative implicature

\footnotetext{
${ }^{21}$ However, as will be shown in the next section, the two may coincide, depending on how an ironic utterance is formulated.
} 
The proposal based on flouting the Relation maxim and as if implicature (subject to negation and conducive to evaluative implicature) may serve as a verisimilar irony recognition procedure, helping distinguish this type of irony from utterances which evince other types of irony or are not ironic at all.

In the next section, a corpus of examples of verisimilar irony found in the academic literature will be critically addressed with a view to specifying a few formal characteristics of verisimilar irony and delineating its scope against the backdrop of other communicative phenomena which may be mistaken for it.

\section{Examples of Verisimilar Irony in the Literature}

Manifestations of verisimilar irony are not easy to appreciate, and its instances are actually rarely to be found in the scholarship. Moreover, many of the examples that can be found are dubious, as will be shown in this section.

\section{Verisimilar Irony (Indeed)}

Apart from the classic mother example, the topical literature offers very few similar instances, such as any of the utterances below said in the event of a driver not having signalled before turning:

(3a) "I (just) love people who signal (when turning)" (Myers Roy 1977: 172, 1978: 17; Gibbs 1986: 4; Kumon-Nakamura et al. 1995; Barbe 1995: 24; Coulson 2005: 129)

(3b) "I just love when people use their turn signals" (Colston 2000: 303)

(3c) "I just love it when people signal before changing lanes" (Gibbs and Colston 2012: 53)

Another example is an utterance produced in the context of someone's having violated the rules of etiquette:

(4) "I love people with good manners" (Haverkate 1990: 92)

The two instances above are amenable to the same type of interpretation as the mother example. First, the hyperbole residing in "love" is teased out. Then, the truthful implicature which flouts the maxim of Relation is transformed into a contextually relevant but untruthful as if implicature ("I appreciate the fact that this driver has used his turn signals" or "I appreciate your good manners"). This as if implicature gives rise to the ultimate evaluative implicature, based on meaning reversal concerning the evaluated activity so that it matches the actual context. This reversal involves also the reversal of evaluation so that it adequately represents the speaker's opinion on this referent vis-à-vis the referent present in what is implicated ("I resent the fact that this driver has failed to use his turn signals" and "I disapprove of your bad manners").

Here is Wilson's (2006: 1726) earlier mentioned example, an utterance made in reference to an over-cautious, neurotic driver: 


\section{(2)}

"I really appreciate cautious drivers"

It shows the same pattern of interpretation but the positive evaluation is not couched in hyperbole. Here, it is what is said that flouts the Relation maxim. Thus, the following as if implicature is engendered "I really appreciate your being a cautious driver" only to be negated and to yield an implicature, such as "I really disapprove of your being such a neurotic (not cautious, in a positive sense) driver". It should be underscored that the epithet "cautious" used with regard to an over-cautious driver is indeed untruthful, just as litotes and hyperbole flout the first maxim of Quality, not Quantity (Grice 1989a [1975]; see Dynel 2016d). What is here endorsed is Grice's view that truthfulness and untruthfulness form a binary opposition, rather than being a matter of degrees.

All of the three instances above all rooted in the speaker's truthful expression of some form of appreciation of a chosen category of people, the appreciation which is inapplicable to the target of irony. Haverkate (1990) captures this under the notion of referential defocalisation, i.e. the person or thing targeted by irony does not belong to the class of people referred to in the utterance. Hence, the target of irony is criticised on the grounds of him/her "not being a member of that category" (Gibbs and Colston 2012: 53). Given the interpretative model put forward here, it should be added that the attempt at eradicating the Relation maxim flouting relies heavily on perceiving the target of irony as being a member of the positively evaluated category at the stage of the as if implicature. The ultimate conclusion is that the target is not such a member, thereby being evaluated negatively. Attardo (2000: 816) provides a slightly different example, compared to the ones presented above, because it does not pivot on a category presented in the form of a plural noun:

(5) “Two farmers in a drought-stricken area are talking and farmer A says: 'Don't you just love a nice spring rain?'”

This verisimilar ironic utterance is couched in a hyperbolic verb and a rhetorical question. Most importantly, it centres on a positive evaluation (in this case, a firstorder implicature, based on the other figures), yet not of a group of people but of a natural phenomenon. In this case, the aspect of category non-membership presents itself otherwise (cf. "rain" does not include "drought", which is a markedly distinct weather condition). Once both the rhetorical question and the hyperbole are accounted for, this utterance may be taken to carry a truthful implicature: "I like nice spring rain", which stands in marked contrast to the drought that the interlocutors have been experiencing. The as if implicature which makes this spontaneously produced utterance fit the context in accordance with the Relation maxim might read along the lines of: "I like this nice spring rain that is falling now". After the necessary meaning reversal which captures the actual context and the adequate evaluation, the farmer's utterance implicates "I resent the drought".

Based on the examples quoted so far, one may gain a wrong impression that verisimilar irony can only be based on an utterance which is hinged on an evaluative verb (such as "love/like" or "appreciate" typical of the oft-quoted examples) conveying the speaker's genuine likes, preferences, etc., which are at odds with (or have not been satisfied by) the action or utterance referred to, which constitutes the 
context of the ironic utterance. Nonetheless, alternatively, a verisimilar ironic utterance may rely on different evaluative expressions. Myers Roy (1978: 143) and Haverkate (1990: 92) provide an example of verisimilar irony which changes the well-entrenched formula by being devoid of an evaluative verb but is contingent of "referential defocalisation" promoted by a singular noun:

(6) "There's nothing like a delicious meal" (uttered in a restaurant of mediocre quality)

Whilst an evaluative verb is not present, this utterance is also evidently evaluative. "There's nothing like" is a conventional formula for praising something. Thus, the as if implicature arising from this utterance is "This is a delicious meal", which, at least from the speaker's perspective, is not true. Incidentally, this example proves that the contextual factors are not always unequivocal and depend on what the speaker believes the context (and the referent) to be (cf. truthfulness), being a matter of subjective judgement. However, for irony to succeed, the speaker and hearer should concur in their evaluations. As a result of meaning negation, the ultimate meaning communicated is "This is a disgusting meal". This instance also bears out that the meaning reversal of an as if implicature may consist in reversing only one structural element, the evaluative word, with the real state of affairs being thus distorted when the as if implicature is formulated.

What can be extrapolated from these validated examples of verisimilar irony is that it consists in utterances communicating positive evaluation of a generic referent (in what is said or implicated) in order to communicate the focal implicature concerning the targeted ironic referent, which is not included in this positively evaluated generic referent, and which is hence evaluated negatively. The truthful meaning coincides with the speaker's positive evaluation expressed in a context in which it does not apply, and apropos of a referent to which it does not apply. This positive evaluation may take many forms and guises (e.g. evaluative verbs, adjectives or conventionalised evaluative formulae). For instance, the mother in the proverbial example could also say the following things to criticise her son for his untidy room: "Having a child who can keep his room clean is so nice", "There's nothing that can make a mother happier than her child's tidiness", or "The ability to keep one's room clean is such a virtue". This positive evaluation seems to be a necessary component of verisimilar irony, which ultimately carries negative evaluation, as all irony does (Grice 1989b [1978]; see Garmendia 2010, 2014; Dynel 2016a), of the target concerning a specific referent. Additionally, in verisimilar irony, the target negatively evaluated in the ultimate implicature is an entity distinct from the object of positive evaluation in what is said or non-ironically implicated. The positive and ironically implicated negative evaluations are typically opposites, insofar as the feature that is truthfully positively evaluated does not apply to the targeted referent, which is thereby negatively evaluated.

\section{What Verisimilar Irony Is Not}

The (verisimilar) ironic status of many examples found in the scholarship is questionable. As will be shown in this section, very frequently, examples used to 
corroborate a statement that irony need not involve untruthfulness, the flouting of the first maxim of Quality, or meaning negation can hardly qualify as irony in a technical sense. They may be considered cases of humour (see Dynel 2013b, 2014) or biting and witty criticism, and thus sarcasm (see Dynel 2016a, 2017c for discussion of the differences between irony and sarcasm). Based solely on the authors' intuitions, rather than precise formal definitions, such examples of verisimilar irony show typological problems but tend to reverberate across the literature, being unquestioningly cited. Apart from being counter-intuitive, such instances will not be amenable to the interpretative model of verisimilar irony proposed here and they will not display the formal characteristics that the examples examined above do show. In the discussion below, however, not to commit the mistake of circular reasoning, the problematic examples will be discussed otherwise, that is by criticising the quoted author's explanations of the workings of these examples without resorting to the notions of implicit untruthfulness or as if implicature put forward here. The central jointly sufficient conditions for verisimilar irony, which the examples below are shown not to fulfil, can be summarised as follows: what is said/implicated carries positive evaluation of the generic referent, which is irrelevant in the context at hand, for the generic referent does not encompass the targeted ironic referent, evaluated negatively in the ultimate implicature.

Moreover, as will transpire, many of these examples fail to meet two criteria that help verify the presence of all irony, according to some researchers (see Kapogianni 2011, 2013, 2016 $\mathrm{a}^{22}$ ): implicated negative evaluation (see Dynel 2013a, 2016a), here seen as evaluative implicature; and a mismatch between an utterance and the context in which it occurs (cf. Colston 1997, 2002; Colston and Keller 1998; Colston and O'Brien 2000; Burgers et al. 2011, 2012; Kapogianni 2011, 2013, 2016a), whether verbal or non-verbal, necessarily as recognised by the speaker (vide the notion of truthfulness and the belief-based approach endorsed here). ${ }^{23}$ As is argued here, the latter aspect translates into the speaker's overt untruthfulness (transparent to the hearer who shares the same context). Whilst in non-verisimilar irony, overt untruthfulness is explicit, i.e. the untruthfulness arises on the utterance level, in verisimilar irony, it is only implicit.

One of the dubious examples is the oft-quoted comment on someone arrogant vaunting their knowledge:

(7) "You sure know a lot" (Kumon-Nakamura et al. 1995: 7; Colston 2000: 280; Garmendia 2011: 59; Camp 2012: 596, 606, 619)

\footnotetext{
22 Kapogianni also provides the condition of violated expectations or norms, whether foregrounded or tacit. However, this concomitant of irony seems to be inextricably connected with the implicated evaluation condition. It is the reason for using irony. Also, it may sometimes be elusive to capture, being more of logical extrapolation from a given example. However, it will always be present when the other two conditions for irony are met.

${ }^{23}$ Whilst the context condition is central in the case of verisimilar irony, it does not appear to be a necessary condition for all ironic utterances, which may look contextually adequate but misrepresent the speaker's beliefs (cf. overt untruthfulness).
} 
A view prevails that this is a true but ironic assertion, here what is said. However, Kumon-Nakamura et al. (1995), the first to have used this example, introduce it (but hardly discuss it) as an "insincere compliment", because the attitude expressed is counter to the surface form of the "assertion". In her discussion of this example, Garmendia (2011: 60) claims that the hearer realises that the speaker's utterance does not match the "motivating belief's referential content" of the speaker, i.e. that the hearer was showing off his knowledge. Although this may indeed be the case, it is difficult to gather how the hearer's discovery of this meaning could be described in technical terms. This explanation does not seem to suffice to motive this example's ironic character. This indicates a drawback of Garmendia's $(2010,2011)$ Asif-Theory, ${ }^{24}$ which may not be able to distinguish between ironic utterances and utterances which engender non-ironic but also evaluative implicatures.

Camp (2012), on the other hand, claims that this example represents "illocutionary sarcasm" 25 as long as this is an assertion (and should it not be, her “propositional sarcasm" would apply). In Camp's view, this instance is anchored in pretence residing in the implicature that the speaker is paying the hearer a compliment, which is actually an insult, insofar as the speaker values other virtues more than knowledge, contrary to what the utterance suggests. However, for lack of adequate evidence, it is disputable whether the speaker does implicate that he/she values the hearer's other merits. Most importantly, Camp (2012: 619) suggests that the speaker "merely pretends to presuppose that knowledge ranks high", which is at odds with the well-entrenched assumption that the speaker makes an assertion, an assumption to which Camp seems to subscribe. If such overt pretence (coinciding with overt untruthfulness) is involved, this utterance should not be seen as verisimilar irony.

On balance, a different explanation needs to be sought for this example. If the speaker should genuinely believe that the hearer knows a lot, this utterance counts as a statement of a fact, and a non-ironic but sarcastic utterance that carries implicit criticism of the hearer's boastfulness. Next to what is said (conveying the speaker's true belief), the focal utterance carries an evaluative implicature dependent on Quantity (saying too little) and Manner floutings (cf. "I do realise you know a lot, but I wish you would stop bragging"). The manner of presentation which is untypical of compliments and suggests the speaker's distancing from the belief will inspire the inferential process that the message is critical. Overall, although this utterance may have originated in the speaker's disappointment with the bragging person's behaviour and carries evaluative implicature, this implicature does not arise from any form of untruthfulness, and no contrast between the utterance and the context is perceptible.

On the other hand, it is indeed the case that this utterance meets the condition of truthful positive evaluation coupled with implicated negative evaluation (part of the global conditions for the presence of verisimilar irony, as proposed above). However, the positive evaluation in what is said is contextually insufficient, rather than contextually incompatible. The contextual incompatibility/irrelevance is a

\footnotetext{
24 This theory should not be mistaken for the notion of as if implicature proposed here.

25 “Sarcasm” is essentially Camp's (2012) label for "irony" (see Dynel 2017c).
} 
necessary condition for verisimilar irony, a condition which this instance does not meet. Additionally, this example does not follow the standard pattern whereby the generic referent evaluated positively does not encompass the targeted referent of irony evaluated negatively, insofar as the positive evaluation and negative evaluation share one referent. These are the reasons why this utterance cannot count as verisimilar irony. ${ }^{26}$

If this utterance is to be seen as being ironic, the speaker cannot subscribe to the opinion expressed, at least the moment he/she is voicing it (even if generally, or on other occasions, the speaker may think the hearer to be knowledgeable), thereby being overtly untruthful (cf. "You do nothing but brag, but you barely know anything on this topic"). If indeed ironic, this example will qualify as standard propositional negation irony (cf. Dynel 2013a).

Analogous specious claims concerning examples representing what is here dubbed verisimilar irony can be found in the various indications of other floutings as triggers of irony (Sperber and Wilson 1981; Kaufer 1981; Attardo 2000; Colston 2000). ${ }^{27}$ As already signalled, Colston (2000) argues that irony may rely on floutings of maxims other than the first Quality maxim. Such irony will then involve "sincerity", here referred to as "truthfulness", which is why it must fall into the scope of verisimilar irony. For instance, Colston (2000: 314) claims that someone who, having heard a weather report forecasting clear skies, says:

"It's raining"

produces irony based on flouting the second maxim of Quantity. This utterance appears to be a statement of a fact perceived by the speaker, generating both nonevaluative what is said and possibly an evaluative implicature ("The forecast was wrong"), as long as the speaker means to allude to the earlier forecast and his/her defeated expectations, which is not quite clear given the way Colston presents this example. Also, no contrast between the utterance and the context can be observed, since it is raining indeed. If this example represented irony, it would follow that all implicated critical meanings are tantamount to ironic language use.

Another case concerns the alleged irony stemming from the flouting the Manner maxims, but not the first Quality maxim. The example which Colston (2000: 314) provides is a reply to a question as to which of the hundreds of red cars in the parking lot is the one to be hired:

"The red one."

This may be a potentially humorous reply or a sharp retort, depending on whether the speaker means to amuse the hearer or merely bitingly comment on the uncanny and annoying situation, but it is by no means based on (verisimilar) irony. Given Colston's insufficient description of this example, it is difficult to conceive of what

\footnotetext{
${ }^{26}$ I would like to thank an anonymous referee for inspiring me to make this elaboration. The same line of reasoning applies to an example offered by the referee, which I consider not to be ironic: "She's careful with her own money", which next to what is said carries an implicature "but she's careless with other people's money".

27 The examples of understatement presented as Quantity floutings are indeed ironic. Nonetheless, understatement is based on flouting the first Quality maxim (see Dynel 2016d).
} 
evaluative implicature this utterance could carry, and it clearly does not display any literal evaluation or utterance versus context contrast.

On the other hand, Kaufer (1981: 502) asserts that irony may arise even if all maxims should be followed, quoting the following example:

$$
\text { "America's allies-always there when they need you," }
$$

which, in his view, "is undeniably crafted as irony because of its obvious contrast with a much more common slogan that conveys an attitude diametrically opposed" (Kaufer 1981: 502). However, while this example may be bitingly witty and may indeed convey criticism, it can hardly be said to be ironic, contrary to what other authors who quote this example also suggest (Attardo 2000: 798; Partington 2006: 187, 2007: 1549). The mere fact that it alludes to and distorts the well known slogan ("America's allies-always there when you need them") and reverses the favourable evaluation of friends/allies (Partington 2006) does not suffice as a basis for labelling it ironic. In this example, even if some tacit disappointment can be intuitively felt, no evaluative implicature or utterance versus (believed) context contrast comes into play.

In a similar vein, the following utterances exemplify irony that may be seen to be rooted in truthful what is said:

(11a) "Friends are always there when they need us" which is said by a person who has been taken advantage of by his friends (Hamamoto 1998: 261)

(11b) "Our friends are always there when they need us" (Martin 1992: 81)

As Martin (1992: 82) rightly acknowledges, this proposition is "truthful (since truth in matters of language is only what is vouched for by the speaker)", but he also insists that it is ironic because it echoes legitimate expectations, which are disappointed. This utterance does indeed depict the speaker's genuine belief, and it does allude to the expectations people have of their friends, but it is by no means an ironic one, contrary to what the two authors suggest. ${ }^{28}$ It does not even carry any evaluative implicature, which is the primary characteristic feature of irony, admittedly the one easiest to detect. Also, in Hamamoto's (1998) version, where some context is depicted, no utterance versus believed context contrast can be found. In either form, his example is contingent on explicit means of expression, whereby the speaker criticises his friends in a straightforward manner, albeit alluding to the well-known saying. All this signals also that the notion of an echo/mention alone, the bedrock premise of the relevance-theoretic approach, is not a sufficient condition for the presence of irony.

Discussing the relevance-theoretic approach, Martin (1992: 82) gives two more examples of irony based on a "statement about reality" or "telling the truth".

(12) "I have to say that what tortured me most in watching this film was boredom" taken from a review of a film entitled "Torture"

\footnotetext{
28 Interestingly, Martin (1992) calls into question the ironic status of this example, albeit focusing only on the meaning of the word "friends", who are not true friends if they cannot be counted on. He ultimately indicates, however, that "friends" should be understood in a broad sense, showing also a smaller degree of typicality, and thus he concludes that the utterance is ironic.
} 
(13) "Christmas and New Year tribulations," said by a person overwhelmed by extravagant celebrations

Both the examples seem to capitalise on wordplay or allusions (a punning reference to the film title, and sound similarity between "tribulations" and the invoked "celebrations"), but can hardly be viewed as ironic. These may be sarcastically critical or humorous utterances but they are clearly devoid of irony, for they do not show any implicitness, let alone promote negatively evaluative implicatures, with the criticism being explicitly communicated. Nor do they meet the condition of believed context versus utterance mismatch that holds for all irony.

At this point, another similar candidate for verisimilar irony should be addressed. It is pivoted on wordplay and a distortion of a proverb and is claimed to represent irony which "describes a state of affairs" (Hamamoto 1998: 262, cf. example 11a):

(14) "A stitch in time saves none!" said by someone who thought he had mended his umbrella only to discover that his attempt had not been successful

This is clearly an allusion to the well-known proverb "A stitch in time saves nine", which is distorted via a pun so that its inapplicability in the situation at hand can be underscored. This humorous utterance, however, does not show the features of irony. Again, no evaluative implicature or contrast between an utterance and its context can be found here, whilst the speaker may be seen to deploy selfdeprecating humour. This example may also be regarded as an acknowledgement of irony of fate (i.e. taking precautionary measures has turned out to be of no avail). This, in turn, might indicate that Hamamoto's (1998: 261) specious proposal of "ironical utterances which describe a state of affairs" (cf. examples 11a and 14) is rooted in a misguided conflation of irony of fate with irony understood as a figure of speech (see Dynel 2017c). Importantly, Hamamoto (1998: 261) ${ }^{29}$ differentiates between this form of irony and irony based on "dissociation from a state of affairs", which is epitomised by the mother example. Indeed, "describing a state of affairs", conceptualised as truthfulness (i.e. what the speaker believes to be a state of affairs), is also a feature of verisimilar irony. Overall, Hamamoto's (1998) distinction is quite vague and the two types of irony can hardly be distinguished, purporting to coincide with verisimilar irony [cf. Martin's (1992) treatment of example 11b], but are not irony at all. The same applies to Hamamoto's (1998: 261) instance which illustrates "dissociation from a state of affairs", next to the proverbial mother example $^{30}$ :

(15) "Our home is an environment," said by a son of two zealous environmental activists, who spend very little time at home

According to Hamamoto (1998: 261), the speaker "dissociates himself from the situation where his house has been neglected and left messy by his parents." By

\footnotetext{
29 Hamamoto (1998: 261) also distinguishes irony which capitalises on "dissociation from an echoed opinion" (i.e. "regular irony").

30 Since Hamamoto (1998) provides very little explanation, it is difficult to appreciate what this dissociation involves, and how the classic verisimilar ironic example can be elaborated.
} 
expressing his true opinion, the speaker criticises the current state of affairs. Nonetheless, it is doubtful whether this example represents verisimilar irony. This is mainly because this example does not seem to rely on positive evaluation arising at the first stage of interpretation, which is a sine qua non for verisimilar irony. It does display contextual irrelevance, but this is related to the implicit overt untruthfulness, typical of standard irony. Specifically, the boy's utterance may be regarded as resting on a metaphor, ${ }^{31}$ a distinct figure involving the flouting of the first maxim of Quality, which has to be teased out first (see Dynel 2016d). "Home" is compared to "environment", and the speaker makes as if to imply that his home is looked after, too, since this is what "environment" means to the parents (cf. the overtly untruthful as if implicature: "Our home is looked after"). This as if implicature arising from the metaphor's elucidation represents standard propositional negation irony, because it is not the case that the boy's home is actually taken care of, which serves as the basis for the final negatively evaluative implicature concerning the parents' behaviour (e.g. "I disapprove of your not taking care of our home.").

Alternatively, the boy's utterance may be interpreted as a non-ironic reproach coupled with an implicit request, based on the speaker's true belief (especially if the statement is uttered in a plaintive voice). The metaphorically expressed truthful but non-evaluative implicature may read: "I believe that our home needs to be looked after." When paraphrased, the ultimate implicature will be: "You must take care of our home, as you take care of the environment" (cf. Sperber and Wilson 1998). According to this interpretation, the boy's utterance also carries implicit criticism of the parents' negligence, but it does not bear the intrinsic features of irony. It must again be stressed that not all negatively evaluative implicatures are connected with irony.

For their part, Sperber and Wilson (1998) view the boy's utterance as an echo sufficient for it to be classified as irony. Sperber and Wilson (1998: 288-289) state that the speaker "is echoing approvingly a thought that his parents should have" while dissociating himself "from the assumption implicit in this echo that his parents do have that thought". This line of reasoning is hardly convincing. The shortcomings of the echo-mention approach aside (cf. Roguska 2007), this example escapes the relevance-theoretic explanation of irony as an echo combined with a dissociative attitude towards the echoed utterance (not any assumptions implicit in an echo). If the boy's utterance were really an instance of irony capitalising on an act of "approvingly echoing", any reproach produced as a truthful (positively evaluative) statement, of which the criticised individual does not seem to be supportive, would need to be ironic. For example, saying "Porridge is very nice" to a child who will not eat it and insists that it is disgusting would need to be regarded as irony.

\footnotetext{
31 The following interpretation is done on the assumption that this indefinite article is merely indicative of Hamamoto's non-native use of English, and "the environment" is the intended version. If "an environment" is really intended (i.e. "a general situation one is in"), the metaphorical interpretation crumbles.
} 
Yet another example which is claimed to represent verisimilar irony is a reply:
"He had nice shoes" to a question "How was your blind date?" (Winner
1988: 6; Barbe 1995: 25; Garmendia 2014: 646, 2015: 68)

On the understanding that the utterance above represents the speaker's true belief (the woman did find the man's shoes nice), this utterance can hardly count as irony. It may convey a critical implicature ("There's nothing I liked about my blind date except for the man's shoes, and this can hardly count as a redeeming feature"), but this does not suffice for the utterance to be classified as irony. If it were, practically any utterance conveying any evaluative implicature next to what is said would need to be classified as irony, and that would be a spurious argument. In this case, the critical reply recruits the flouting of the first Quantity maxim (she gives insufficient information relative to the question), and possibly also Manner maxims. Most importantly, it might be argued that it is also the Relation maxim that is flouted, inasmuch as the reply does not concern the blind date but focuses on a detail which may be considered to be of secondary importance, if not entirely insignificant. Thereby, the speaker implicates that she does not think much of her blind date, and may also mean to amuse the hearer by making this utterance in a witty, biting manner, which is why it may be considered sarcastic, but not ironic (cf. Dynel 2016a, 2017c). All the floutings give rise to a non-ironic evaluative implicature ("It was awful"), not an as if implicature along the lines: "The date was great, because he had nice shoes" as a springboard for "The date was awful, because he had nice shoes", which would be logically ill-founded. Clearly, the evaluative implicature arises differently, on a non-ironic inferential path: the flouting of the different maxims leads directly to the pivotal evaluative implicature.

Incidentally, this discussion brings to mind Grice's (1989a [1975]: 33) wellknown example by dint of which he illustrates the flouting of the first maxim of Quantity, namely a written testimonial about a candidate for a philosophy job: "Dear Sir, Mr. X's command of English is excellent, and his attendance at tutorials has been regular. Yours, etc." Grice (1989a [1975]: 33) suggests that the letter's author "must be wishing to impart information that he is reluctant to write down. This supposition is tenable only if he thinks Mr. X [the candidate] is no good at philosophy. This, then, is what he is implicating." It is perhaps out of politeness (and not with a view to amusing the addressee, as in the failed date example) that the author does not assert that the candidate has insufficient skills, by flouting the first maxim Quantity and provides truthful but insufficient (and also irrelevant) information to convey an implicature that carries negative evaluation. Needless to say, this example does not display any type of irony.

Another similar candidate for verisimilar irony can be found in the following exchange between A (willing to know the reason for B's sudden departure) and B:
A: "What's in the airport?"
B: "Planes" (Kapogianni 2013: 55, 2014: 599 translated from Greek)

By this answer, as Kapogianni claims, the speaker implicates that the question is annoying. In Kapogianni's (2013) account, the reply flouts the first maxim of Quantity by being uninformative, whilst not flouting Quality. The reply also flies in 
the face of contextual relevance since it does not answer the question only to evaluate it critically. Kapogianni (2013) considers this to be an instance of "meaning replacement irony", specifically a context-driven incongruous response, which involves "an obvious answer to a silly question", whereby the question is negatively evaluated. However, a pending query is whether this reply that communicates obvious and insufficient information, in actual fact, is irony. Whilst the speaker may indeed tacitly communicate that he/she is not willing to provide a relevant answer by being evasive, it seems unfounded (at least, without sufficient context) to claim that the focal utterance involves a negative evaluation of the preceding utterance (with such evaluation being a sine qua non for this type of irony). Depending on the speaker's attitude, this utterance can be regarded as either non-ironic sarcasm (with the utterance being tantamount to "That's none of your business") or playful teasing (Dynel 2014).

A few more potential candidates for verisimilar irony come from Camp (2012), who distinguishes a type of irony which concerns only implicatures generated by assertions (here, conceptualised as statement-based what is said). To substantiate this claim, she provides a number of examples, including "You sure know a lot" discussed above, and a few other ones, yet not explaining in detail how the ironic implicatures come into being. As a matter of fact, not all of the examples she provides can be seen as relying on "ironic implicatures" at all. For instance,

"Would you mind very much if I asked you to consider cleaning up your room some time this year?"

can hardly be taken as fostering an implicature that the "request is supererogatory" (Camp 2012: 596). This example is more a matter of what may be called pragmatic meaning reversal irony (see Dynel 2013a), which does involve overt untruthfulness at the utterance level. Thereby, the speaker merely overtly pretends to make a very polite request, whilst ordering the hearer to do the cleaning. Also, Camp's (2012) claim that this example involves ironic manner of expression is elusive. Irony needs to be defined in terms of formal criteria, such as those proposed here, whilst nonverbal cues, optional and ambivalent as they are, do not count as such.

Two other examples Camp (2012) provides as cases of irony which targets only implicature, with the semantic content being asserted, are particularly interesting. One of them is Bredin's (1997: 7):

(19) "The hotel room costs a thousand dollars a night. Of course, for that you get a half bottle of Australian champagne and your breakfast thrown in" (Camp 2012: 596)

Bredin (1997: 7) views it as a peculiar manifestation of irony which operates on "an implicatum as well as the sentence meaning — an implicatum which attaches to the sentence before the irony begins to kick in." Following this train of thought, Camp (2012) argues that the irony in this example is promoted only by implicature. In her view, the irony-carrying implicature is that the hotel room is still good value for money or that the extortionate price is offset by the complimentary drink and breakfast. Nonetheless, neither of the authors attempts to explain how this interpretation actually arises. Indeed, the ultimate implicature carrying negative 
evaluation $^{32}$ is: "The hotel is extremely expensive, and half a bottle of champagne and a complimentary breakfast do not make up for the exorbitant price". However, a query remains as to whether this instance represents verisimilar irony, namely whether the utterance is unequivocally truthful. It can be claimed that the disjunct opening the second sentence, "of course", is used untruthfully (for irony centred on isolated lexical items, see Wilson 2006; Camp 2012; Dynel 2013a). Without this disjunct, the second sentence would lose its ironic nature, albeit being still implicitly critical. Essentially, the speaker deems it preposterous that a breakfast and some champagne (not even a whole bottle) should balance the cost, which is a matter of logical inference based on the background premises available to the interlocutors. The speaker is not truly indicating that the hearer must already know that what the speaker is saying is true or that the hearer expects this information, as the literal reading of "of course" would indicate. "Of course" is then used ironically, i.e. it is overtly untruthful. The ironic disjunct sheds new ironic light on the otherwise truthful proposition. On the whole, the utterance does display overt explicit untruthfulness typical of meaning reversal irony. Hence, it does not qualify as verisimilar irony.

Another very similar example that Camp (2012: 596) gives involves a conversational exchange:

(20) " $A$ : I'm sorry Aunt Louisa is such a bother. $B$ : Oh, she never stays for more than a month at a time, and she always confines her three cats to the upper two floors of our house."

Camp (2012) suggests that it is only the implicature that the visits are non-imposing that accounts for the irony in B's reply. The ultimate evaluative implicature is, therefore, that the speaker finds the visits bothersome. Indeed, at first glance, the example depends on the speaker's truthfulness at the level of what is said. The negative evaluation is a matter of an evaluative implicature arising from what is said, given the preceding turn: a month's stay is a long time and keeping one's pets on two floors of someone's house means occupying a lot of space. The two facts are phrased in a way that ostensibly minimises the aunt's imposition, which contributes to the critical effect. Doubt may be cast on whether the utterance is genuinely truthful in its entirety, though. It seems that it is anchored in an ironic use of "oh". Devoid of this interjection, the utterance would lose its ironic character, even though it would still be considered sarcastic, with the negative evaluation having to be inferred. The interjection suggests that speaker B does not agree with the interlocutor's negative evaluation of the person in question. Whilst the main proposition is indeed truthful ("Aunt Louisa always stays a month or less and keeps her cats on two floors"), the ironic interjection seems to suggest untruthfully that the speaker makes light of the aunt's visits, finding them unproblematic, and thus it renders the intended meaning at the level of what is said overtly untruthful. Consequently, the speaker's meaning may be paraphrased as follows "I don't find it

\footnotetext{
32 This utterance need not convey any negative evaluation at all if uttered by an affluent person, who merely describes the facts and does not find the hotel unaffordable, even if expensive. This is hardly surprising for, if the negative evaluation is a conversational implicature, it is always possible to find a context in which it will not be triggered.
} 
a nuisance that Aunt Louisa always stays a month or less, and keeps her cats on two floors", which further promotes the focal implicature along the standard lines of propositional meaning reversal. This is then an example of irony involving overt explicit untruthfulness, and it cannot be seen as verisimilar irony. Generally, thanks to their bitingly critical potential, Camp's examples presented here may be taken as representing not irony but sarcasm (see Dynel 2017c for the distinction). Incidentally, the latter is the label Camp uses, although her focus is clearly the figure of irony.

An example similar to Camp's can be found in Currie (2006). In his pretence proposal for irony, Currie (2006: 120) argues in favour of a "pretence of manner", which enables the ironic speaker to "utter an assertoric sentence ironically, and at the same time really be asserting it." To illustrate this point, he provides the example of two passengers on a plane that touches down in both Melbourne and Anchorage. Although all signs indicate they are in Melbourne, one of the passengers asks where they are only to receive the fellow passenger's reply:

"Well, we are either in Melbourne or in Anchorage."

Currie (2006) maintains that the ironic speaker is making an assertion "yet pretending to have the kind of interest in it we normally have in disjunctions: namely, its providing us with the basis for an inference, should further information come in, of the form A or B, not A, so B, and so getting us to a definite conclusion about where we are" (2006: 120). Indeed, the speaker may be taken to be overtly pretending in the Gricean sense, and thus only making as if to assert. This overt pretence underlies the focal disjunction, which seems to suggest the speaker's doubt as to which of the alternatives is the correct one, as indicated also by the ironic "well", which marks the speaker's overtly pretended hesitation. It is not the case that the speaker is in any doubt as to their whereabouts, which he only overtly pretends. This utterance is overtly untruthful. Therefore, it does not qualify as verisimilar irony. If, however, the utterance were a genuine assertion and the speaker were making a logical statement (cf. "We are either in Melbourne or in Anchorage, but not anywhere else, and not in both at the same time"), he would not be able to be seemingly hesitant or doubtful, and hence ironic, at the same time. Therefore, he would not be able to communicate the central implicit evaluative meaning the ironic reading affords, namely an implicit criticism of the silly question.

In the light of all this, one may conclude that none of the candidates examined in this section disconfirms the assumption that verisimilar irony must rely on utterances carrying explicit or implicit evaluation which tallies with the speaker's genuine beliefs but is irrelevant to the referent of evaluation in the context at hand. Overall, whilst verisimilar irony is rarely the central topic of investigation and few validated examples can be found in the literature, most of the instances compiled and discussed in this section testify that some authors tend to overestimate the scope of verisimilar irony and see it also in utterances whose ironic status can be questioned, if approached formally, or which represent other types of irony. Verisimilar irony appears to be a narrow-scope phenomenon which resides in truthful what is said or truthful implicature which carries positive evaluation but 
which is contextually incompatible, i.e. it does not fit the speaker-believed context. This contextual irrelevance and the clash between the truthful meaning and the context is what triggers the inferential process of searching for the implicated meaning, which ultimately leads to a negative evaluation of the referent at hand.

\section{Conclusions}

This paper has addressed the topic of verisimilar irony, which seems to fly in the face of Grice's sketchy conceptualisation of irony. As defined here, this nonprototypical type of irony revolves around truthful meanings: the Gricean notions of what is said or implicature (especially if another non-ironic flouting of the first maxim of Quality is in operation), which do not immediately invite meaning negation. The speaker does communicate his/her true belief (via what is said or implicature) but primarily intends to convey the focal evaluative implicature. Therefore, verisimilar irony is different from standard meaning reversal irony because it does not originate from "making as if to say" and does not present ironyrelated overt explicit untruthfulness. Consequently, verisimilar irony may, at first blush, be regarded as escaping, and thus discrediting, the Gricean account.

However, it was here argued that Grice may not have conceived of verisimilar irony, but the notions he proposed do help explain its emergence (production and reception) in theoretical terms, a goal which previous accounts of irony do not appear to have attained. The central postulate advanced here is that the focal evaluative implicature arises from overt implicit untruthfulness embedded in the Relation maxim's flouting which gives rise to an untruthful as if implicature. Verisimilar irony is grounded on a contrast between truthful what is said or what is non-ironically implicated and the contextual factors which determine the referent of ironic evaluation, as seen by the speaker and, prototypically, duly recognised by the hearer. The focal negatively evaluative implicature is piggybacked on an (untruthful) as if implicature, which does not constitute speaker meaning and is subject to meaning reversal in order to be compatible with the context and with the nature of the ironic referent, and in order to capture the speaker's genuine evaluation of it.

A survey of the relevant literature was conducted in pursuit of examples of verisimilar irony in order to validate the diversity of this figure, and consequently to verify the applicability of the proposed interpretative model. In the light of the analysis, it transpires that verisimilar ironic utterances share two formal characteristics. A verisimilar ironic utterance carries truthful positive evaluation of the generic referent (in what is said or implicated), but it is incompatible with the context in which it is uttered. On the other hand, it was also shown that a large proportion of examples seen by other authors as verisimilar irony either does not constitute irony at all or represents irony not dependent on truthful what is said or implicature. Consequently, a thesis can be formulated that verisimilar irony exhibits a narrow range of manifestations, being restricted to utterances which convey truthful evaluation (in various forms and guises) of a generic referent which is not relevant to the referent of the focal ironic (negative) evaluation emerging in a given 
context. To examine the internal diversity of verisimilar irony, further corporabased studies are in order, even if datasets of verisimilar ironic utterances may not be easy to obtain. This is how corpus pragmatics can benefit theoretical pragmatics, which tends to deploy only isolated examples, frequently constructed by researchers.

On the other hand, verisimilar irony, like prototypical irony, is not amenable to any simple keyword searches yielding instances of the figure that are exhaustive of the corpus and simultaneously devoid of false positives. However, specific manifestations of irony can definitely be sought on the basis of carefully chosen keywords, notably those carrying the various forms of positive evaluation, which may be implicit, though, and hence more difficult to trace. What may also facilitate such corpus pragmatic studies is the use of corpora that include information about non-verbal factors (notably prosody and facial expressions), which serve as additional cues for (but not unequivocal indicators of) the presence of the focal figure. Ultimately, all instances need to be checked manually and validated in the light of select theoretical postulates, such as the ones proposed in this paper.

Funding This work was supported by the Ministry of Science and Higher Education (Project number IP2015 012874, Decision 0128/IP3/2016/74).

Open Access This article is distributed under the terms of the Creative Commons Attribution 4.0 International License (http://creativecommons.org/licenses/by/4.0/), which permits unrestricted use, distribution, and reproduction in any medium, provided you give appropriate credit to the original author(s) and the source, provide a link to the Creative Commons license, and indicate if changes were made.

\section{References}

Alba-Juez, L. (1998). On the conventionalization of verbal irony in English: A corpus-based study. In I. Vázquez-Orta \& I. Guillén Galve (Eds.), Perspectivas Pragmáticas en Lingüística Aplicada (pp. 11-18). Zagaroza: Anubar.

Attardo, S. (2000). Irony as relevant inappropriateness. Journal of Pragmatics, 32, 793-826.

Barbe, K. (1993). Isn't it ironic that...? Explicit irony markers. Journal of Pragmatics, 20, 578-590.

Barbe, K. (1995). Irony in context. Amsterdam: John Benjamins.

Bredin, H. (1997). The semantic structure of verbal irony. Journal of Literary Semantics, 16, 1-20.

Burgers, C., van Mulken, M., \& Schellens, P. J. (2011). Finding irony: An introduction of the Verbal Irony Procedure (VIP). Metaphor and Symbol, 26(3), 186-205.

Burgers, C., van Mulken, M., \& Schellens, P. J. (2012). Verbal irony: Differences in usage across written genres. Journal of Language and Social Psychology, 31(3), 290-310.

Burgers, C., van Mulken, M., \& Schellens, P. J. (2013). The use of co-textual irony markers in written discourse. Humor: International Journal of Humor Research, 26(1), 45-68.

Camp, E. (2006). Contextualism, metaphor, and what is said. Mind and Language, 21(3), 280-309.

Camp, E. (2012). Sarcasm, pretense, and the semantics/pragmatics distinction. Noûs, 46, 587-634.

Claridge, C. (2001). Approaching irony in corpora. In P. Rayson, A. Wilson, T. McEnery, A. Hardie, \& S. Khoja (Eds.), Proceedings of the Corpus Linguistics 2001 conference. UCREL technical papers (Vol. 13, pp. 134-143). Lancaster: Lancaster University Computer Department.

Colston, H. (1997). Salting a wound or sugaring a pill: The pragmatic functions of ironic criticism. Discourse Processes, 23, 25-45.

Colston, H. (2000). On necessary conditions for verbal irony comprehension. Pragmatics \& Cognition, 8 , 277-324.

Colston, H. (2002). Contrast and assimilation in verbal irony. Journal of Pragmatics, 34, 111-142. 
Colston, H., \& Gibbs, R. (2007). A brief history of irony. In R. Gibbs \& H. Colston (Eds.), Irony in language and thought. A cognitive science reader (pp. 3-21). New York: Lawrence Erlbaum.

Colston, H., \& Keller, S. (1998). You'll never believe this. Irony and hyperbole in expressing surprise. Journal of Psycholinguistic Research, 27, 499-513.

Colston, H., \& O'Brien, J. (2000). Contrast and pragmatics in figurative language: Anything understatement can do, irony can do better. Journal of Pragmatics, 32, 1557-1583.

Coulson, S. (2005). Sarcasm and the space structuring model. In S. Coulson \& B. LewandowskaTomaszczyk (Eds.), The literal and the nonliteral in language and thought (pp. 129-144). Berlin: Peter Lang.

Currie, G. (2006). Why irony is pretence. In S. Nichols (Ed.), The architecture of imagination (pp. 111-133). Oxford: Oxford University Press.

Dynel, M. (2009). Humorous garden-paths: A pragmatic-cognitive study. Newcastle: Cambridge Scholars Publishing.

Dynel, M. (2011). A web of deceit: A neo-Gricean view on types of verbal deception. International Review of Pragmatics, 3(2), 137-165.

Dynel, M. (2013a). Irony from a neo-Gricean perspective: On untruthfulness and evaluative implicature. Intercultural Pragmatics, 10, 403-431.

Dynel, M. (2013b). When does irony tickle the hearer? Towards capturing the characteristics of humorous irony. In M. Dynel (Ed.), Developments in linguistic humour theory (pp. 298-320). Amsterdam: John Benjamins.

Dynel, M. (2014). Isn't it ironic? Defining the scope of humorous irony. Humor, 27, 619-640.

Dynel, M. (2016a). Pejoration via sarcastic irony and sarcasm. In R. Finkenbeiner, J. Meibauer, \& H. Wiese (Eds.), Pejoration (pp. 219-239). Amsterdam: John Benjamins.

Dynel, M. (2016b). Comparing and combining covert and overt untruthfulness: On lying, deception, irony and metaphor. Pragmatics \& Cognition, 23(1), 174-208.

Dynel, M. (2016c). On untruthfulness, its adversaries and strange bedfellows. Pragmatics \& Cognition, $23(1), 1-15$.

Dynel, M. (2016d). Two layers of overt untruthfulness: When irony meets metaphor, hyperbole, or meiosis. Pragmatics \& Cognition, 23(2).

Dynel, M. (2017a). No child's play: A philosophical pragmatic view of overt pretence as a vehicle for conversational humour. In V. Tsakona \& J. Chovanec (Eds.), Creating and negotiating humor in everyday interactions. Amsterdam: John Benjamins.

Dynel, M. (2017b). Implicitness via overt untruthfulness: Grice on Quality-based figures of speech". In P. Cap \& M. Dynel (Eds.), Implicitness: From Lexis to Text. Amsterdam: John Benjamins.

Dynel, M. (2017c). Academics vs. American scriptwriters vs. Academics: A battle over the etic and emic "sarcasm" and "irony" labels. Language \& Communication. doi:10.1016/j.langcom.2016.07.008.

Eisterhold, J., Attardo, S., \& Boxer, D. (2006). Reactions to irony in discourse: Evidence for the least disruption principle. Journal of Pragmatics, 38(8), 1239-1256.

Garmendia, Joana. (2010). Irony is critical. Pragmatics \& Cognition, 18, 397-421.

Garmendia, Joana. (2011). She's (not) a fine friend: "Saying" and criticism in irony. Intercultural Pragmatics, 8, 41-65.

Garmendia, Joana. (2014). The clash: Humor and critical attitude in verbal irony. Humor, 27, 641-660.

Garmendia, Joana. (2015). A (neo)Gricean account of irony: An answer to relevance theory. International Review of Pragmatics, 7, 40-79.

Gibbs, R. (1986). On the psycholinguistics of sarcasm. Journal of Experimental Psychology: General, $105,3-15$.

Gibbs, R. (2000). Irony in talk among friends. Metaphor and Symbol, 15, 5-27.

Gibbs, R., \& Colston, H. (2007). The future of irony studies. In R. Gibbs \& H. Colston (Eds.), Irony in language and thought: A cognitive science reader (pp. 581-595). New York: Erlbaum.

Gibbs, R., \& Colston, H. (2012). Interpreting figurative meaning. New York: CUP.

Gibbs, R., \& O’Brien, J. (1991). Psychological aspects of irony understanding. Journal of Pragmatics, 16, $523-530$.

Giora, R. (2003). On our mind: Salience, context, and figurative language. New York: Oxford University Press.

Giora, R., Drucker, A., \& Fein, O. (2014). Resonating with default nonsalient interpretations: A corpusbased study of negative sarcasm. Belgian Journal of Linguistics, 28, 3-18.

Grice, H. P. (1989a). Logic and conversation. In H. P Grice (Ed.), Studies in the way of words (pp. 22-40). Cambridge, MA: Harvard University Press. [Grice, H. P. (1975). Logic and conversation. In 
P. Cole \& H. Morgan (Eds.), Syntax and semantics: Speech acts (Vol. 3, pp. 41-58). New York: Academic Press; Grice, H. P. (1975). Logic and conversation. In D. Davison \& G. Harman (Eds.), The logic of grammar (pp. 64-75). Dickenson: Encino].

Grice, H. P. (1989b). Further notes on logic and conversation". In H. P. Grice (Ed.), Studies in the way of words (pp. 41-57). Cambridge, MA: Harvard University Press. [Grice, H. P. (1978). Further notes on logic and conversation. In P. Cole (Ed.), Syntax and semantics: Pragmatics (Vol. 9, pp. 113-127). New York: Academic Press].

Hamamoto, H. (1998). Irony from a cognitive perspective. In R. Carston \& S. Uchida (Eds.), Relevance theory: Applications and implications (pp. 257-270). Amsterdam: John Benjamins.

Haverkate, H. (1990). A speech act analysis of irony. Journal of Pragmatics, 14, 77-109.

Jaszczolt, K. (2009). Cancellability and the primary/secondary meaning distinction. Intercultural Pragmatics, 6, 259-289.

Kapogianni, E. (2011). Irony via 'surrealism'. In M. Dynel (Ed.), The pragmatics of humour across discourse domains (pp. 51-68). Amsterdam: John Benjamins.

Kapogianni, E. (2013). Irony and the literal versus nonliteral distinction: A typological approach with focus on ironic implicature strength, Ph.D. thesis. Cambridge: University of Cambridge.

Kapogianni, E. (2014). Differences in use and function of verbal irony between real and fictional discourse: (Mis)interpretation and irony blindness. Humor, 27, 597-618.

Kapogianni, E. (2016a). The ironic operation: Revisiting the components of ironic meaning. Journal of Pragmatics, 91, 16-28.

Kapogianni, E. (2016b). The ironist's intentions: Communicative priority and manifestness. Pragmatics \& Cognition, 23(1), 150-173.

Kaufer, D. (1981). Understanding ironic communication. Journal of Pragmatics, 5, 495-510.

Kumon-Nakamura, S., Glucksberg, S., \& Brown, M. (1995). How about another piece of pie: The allusional pretense theory of discourse irony. Journal of Experimental Psychology: General, 124, 3-21.

Lucariello, J. (1994). Situational irony: A concept of events gone awry. Journal of Experimental Psychology: General, 123(2), 129-145.

Martin, R. (1992). Irony and the universe of belief. Lingua, 87, 77-90.

Myers Roy, A. (1977). Towards a definition of irony. In R. Fasold \& R. Shuy (Eds.), Studies in language variation (pp. 171-183). Washington, DC: Georgetown University Press.

Myers Roy, A. (1978). Irony in conversation. Ann Arbor, ML: University Microfilms International.

Partington, A. (2006). The linguistics of laughter. A corpus-assisted study of laughter-talk. Oxon: Routledge.

Partington, A. (2007). Irony and the reversal of evaluation. Journal of Pragmatics, 39, 1547-1569.

Pelsmaekers, K., \& Van Besien, F. (2002). Subtitling irony: Blackadder in Dutch. The Translator, 8, 241-266.

Popa, M. (2009). Figuring the code: Pragmatic routes to the non-literal. Ph.D. Dissertation, University of Geneva.

Recanati, F. (2004). Literal meaning. Cambridge: Cambridge University Press.

Reyes, A., Rosso, P., \& Buscaldi, D. (2012). From humor recognition to irony detection: The figurative language of social media. Data \& Knowledge Engineering, 74, 1-12.

Reyes, A., Rosso, P., \& Veale, T. (2013). A multidimensional approach for detecting irony in twitter. Language Resources and Evaluation, 47(1), 239-268.

Roguska, M. (2007). Echo and mention in the Dan Sperber and Deidre Wilsons's theory of irony. Linguistische Berichte, 211, 309-330.

Shelley, C. (2001). The bicoherence theory of situational irony. Cognitive Science, 25, 775-818.

Soames, S. (2008). Drawing the line between meaning and implicature-and relating both to assertion. Nô̂s, 42, 440-4655.

Sperber, D., \& Wilson, D. (1981). Irony and the use-mention distinction. In P. Cole (Ed.), Radical pragmatics (pp. 295-318). New York: Academic.

Sperber, D., \& Wilson, D. (1998). Irony and relevance: A reply to Seto, Hamamoto and Yamanashi. In R. Carston \& S. Uchida (Eds.), Relevance theory: Applications and implications (pp. 283-293). Amsterdam: John Benjamins.

Stern, J. (2000). Metaphor in context. Cambridge MA: MIT Press.

Stokke, A. (2013). Lying and asserting. Journal of Philosophy, 110, 33-60.

Taylor, C. (2015). Beyond sarcasm: The metalanguage and structures of mock politeness. Journal of Pragmatics, 87, 127-141. 
Utsumi, A. (2000). Verbal irony as implicit display of ironic environment: Distinguishing ironic utterances from nonirony. Journal of Pragmatics, 32, 1777-1806.

Veale, T. (2013). Strategies and tactics for ironic subversion. In M. Dynel (Ed.), Developments in linguistic humour theory. Amsterdam: John Benjamins.

Veale, T., \& Hao, Y. (2009). Support structures for linguistic creativity: A computational analysis of creative Irony in Similes. In Proceedings of CogSci 2009, the 31st annual meeting of the cognitive science society (pp. 1376-1381).

Vincent Marrelli, J. (2003). Truthfulness. In J. Verschueren, J.-O. Östman, J. Blommaert, \& C. Bulcaen (Eds.), Handbook of pragmatics (pp. 1-48). Amsterdam: John Benjamins.

Vincent Marrelli, J. (2004). Words in the way of truth. Truthfulness, deception, lying across cultures and disciplines. Napoli: Edizione Scientifiche Italiane.

Weizman, E. (2001). Addresser, addressee and target: Negotiating roles through ironic criticism. In E. Weigand \& M. Dascal (Eds.), Negotiation and power in dialogic interaction (pp. 125-137). Amsterdam: John Benjamins.

Wilson, D. (1995). Is there a maxim of truthfulness? UCL Working Papers in Linguistics, 7, 197-212.

Wilson, D. (2006). The pragmatics of verbal irony: Echo or pretence? Lingua, 116, 1722-1743.

Wilson, D., \& Sperber, D. (1992). On verbal irony. Lingua, 87, 53-76.

Wilson, D., \& Sperber, D. (2000). Truthfulness and relevance. UCL Working Papers in Linguistics, 12, 215-254.

Winner, E. (1988). The point of words. Children's Understanding of metaphor and irony. London: Harvard University Press.

Yamanashi, M. (1998). Some issues in the treatment of irony and related tropes. In R. Carston \& S. Uchida (Eds.), Relevance theory: Applications and implications (pp. 271-281). Amsterdam: John Benjamins. 